\title{
MRI prospective survey on cardiac and hepatic iron in transfusion-dependent thalassemia intermedia patients treated with desferrioxamine, deferiprone and deferasirox
}

\author{
Antonella Meloni ${ }^{1 *}$, Mari Giovanna Neri ${ }^{1}$, Maria Chiara Resta ${ }^{2}$, Massimiliano Missere ${ }^{3}$, Antonino Vallone ${ }^{4}$ \\ Vincenzo Positano ${ }^{1}$, Silvia Macchi ${ }^{5}$, Crocetta Argento ${ }^{6}$, Daniele De Marchi ${ }^{1}$, Alessia Pepe ${ }^{1}$
}

From 18th Annual SCMR Scientific Sessions

Nice, France. 4-7 February 2015

\section{Background}

Few studies have evaluated the efficacy of iron chelation therapy in thalassemia intermedia (TI) patients. Our study aimed to prospectively assess by quantitative Magnetic Resonance imaging (MRI) the efficacy of the three available chelators in monotherapy in transfusion dependent (TD) TI patients.

\section{Methods}

Among the 325 TI patients enrolled in the MIOT (Myocardial Iron Overload in Thalassemia) network, we selected 103 TI patients TD with an MRI follow-up (FU) study at $18 \pm 3$ months who had been received one chelator alone between the two MRI scans. Iron overload was assessed by the $\mathrm{T} 2 *$ multiecho technique. Hepatic $\mathrm{T}^{*}$ values were converted into liver iron concentration (LIC) values.

\section{Results}

Three groups of patients were identified: 27 patients (13 females, mean age $40.12 \pm 10.31$ years) treated with desferioxamine (DFO - mean dosage $37.52 \pm 8.69 \mathrm{mg} / \mathrm{kg} /$ die), 23 patients ( 14 females, mean age $34.73 \pm 10.67$ years) treated with deferiprone (DFP- dosage 71.70 $\pm 14.46 \mathrm{mg} / \mathrm{kg} / \mathrm{die}$ ) and 14 patients ( 9 females, mean age $36.63 \pm 10.92$ years) treated with deferasirox (DFX mean dosage $27.75 \pm 5.04 \mathrm{mg} / \mathrm{kg} / \mathrm{die})$. Excellent $/$ good levels of compliance were similar in the DFO (92.6\%), DFP (100\%) and DFX (100\%) groups $(\mathrm{P}=0.345)$. The

\footnotetext{
${ }^{1}$ CMR Unit, Fondazione G. Monasterio CNR-Regione Toscana, Pisa, Italy Full list of author information is available at the end of the article
}

mean starting age of regular transfusion was 14.73 \pm 15.89 years.

At baseline in DFO group two patients (7.4\%) showed a global heart $\mathrm{T} 2 * 20 \mathrm{~ms}$ and one of them showed no cardiac iron at the FU. At baseline in DFP group two patients $(8.7 \%)$ showed a global heart $\mathrm{T} 2 *<20 \mathrm{~ms}$ and one of them showed no cardiac iron at the FU. All the 5 patients (35.7\%) under DFX therapy with pathological global heart $\mathrm{T} 2 *$ at the baseline remained at the same status at the FU. The percentage of patients who maintained a normal global heart $\mathrm{T} 2 \%$ value was comparable for DFO (100\%), DFP (100\%) and DFX (88.9\%) groups $(\mathrm{P}=0.164)$.

Among the 46 patients with hepatic iron at baseline (MRI LIC $\geq 3 \mathrm{mg} / \mathrm{g} / \mathrm{dw}$ ), the reduction in the MRI LIC values was significant only in the DFO group (DFO: $-3.39 \pm 6.38 \mathrm{mg} / \mathrm{g} / \mathrm{dw} \mathrm{P}=0.041$; DFP: $-2.25 \pm 6.01 \mathrm{mg} / \mathrm{g} / \mathrm{dw}$ $\mathrm{P}=0.136$ and DFX: $-0.36 \pm 5.56 \mathrm{mg} / \mathrm{g} / \mathrm{dw} \mathrm{P}=0.875)$. The decrease in MRI LIC values was comparable among the groups $(\mathrm{P}=0.336)$. The number of patients with a MRI $\mathrm{LIC}<3 \mathrm{mg} / \mathrm{g} / \mathrm{dw}$ went up from $10(37 \%)$ to $11(40.7 \%)$ in the DFO group, from $6(26.1 \%)$ to $8(34.8 \%)$ in the DFP group and from $2(14.3 \%)$ to $8(57.1 \%)$ in the DFX group. The percentage of patients who maintained a normal MRI LIC value was comparable for DFO (90\%) vs DFP $(50 \%)$ and DFX (100\%) groups $(\mathrm{P}=0.191)$.

\section{Conclusions}

Prospectively in transfusion-dependent TI patients at the dosages used in the clinical practice, DFO and DFP showed $100 \%$ efficacy in maintaining a normal global 

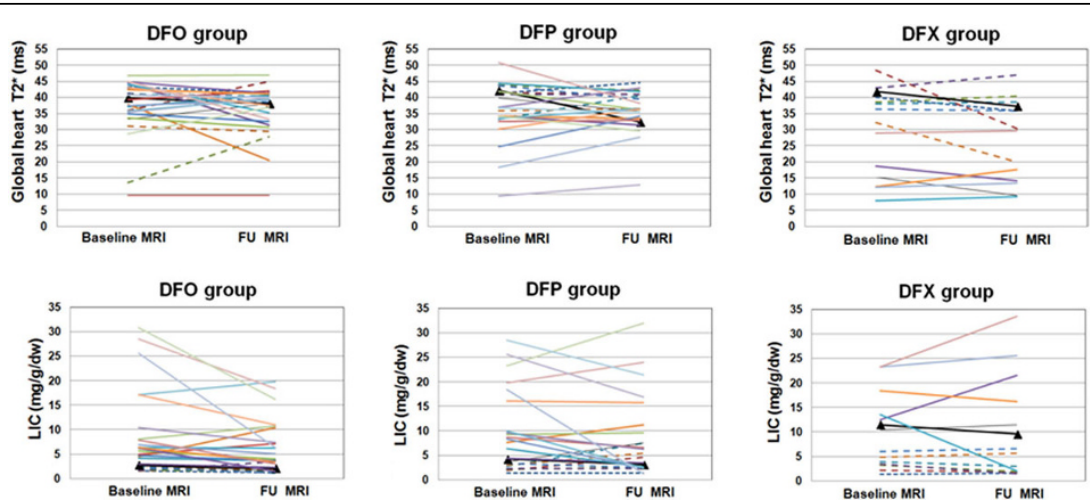

Figure 1 Changes of global haert T2* (up) and MRI LIC values (bottom) in TD TI patients treated with different iron chelators in monotherapy

heart T2* value while DFX had $100 \%$ efficacy in maintaining a normal LIC value.

Further prospective studies involving more patients with iron at the baseline are needed to establish which is the most effective drug in reducing iron levels.

\section{Funding}

The MIOT project receives "no-profit support" from industrial sponsorships (Chiesi Farmaceutici S.p.A. and ApoPharma Inc.).

\section{Authors' details}

${ }^{1}$ CMR Unit, Fondazione G. Monasterio CNR-Regione Toscana, Pisa, Italy.

${ }^{2}$ Struttura Complessa di Radiologia, OSP. SS. Annunziata ASL Taranto,

Taranto, Italy. ${ }^{3}$ Dipartimento di Radiologia, Un. Cattolica del Sacro Cuore -

Centro di Ricerca e Formazione ad Alta Tecnologia "G. Paolo II",

Campobasso, Italy. ${ }^{4}$ Istituto di Radiologia, Az. Osp. "Garibaldi" Presidio

Ospedaliero Nesima, Catania, Italy. ${ }^{5}$ Servizio trasfusionale, Ospedale Santa

Maria delle Croci, Ravenna, Italy. ${ }^{6}$ Centro di Talasssemia, Ospedale San

Giovanni Di Dio, Agrigento, Italy.

Published: 3 February 2015

Submit your next manuscript to BioMed Central and take full advantage of:

- Convenient online submission

- Thorough peer review

- No space constraints or color figure charges

- Immediate publication on acceptance

- Inclusion in PubMed, CAS, Scopus and Google Scholar

- Research which is freely available for redistribution 